The Journal of Engineering and Exact Sciences - JCEC, Vol. 04 N. 04 (2018)

journal homepage: https://jcec.ufv.br

doi: https://doi.org/10.18540/jcecvl4iss4pp0445-0449

OPEN ACCESS - ISSN: 2527-1075

\title{
ESTUDO DE VIABILIDADE ECONÔMICA DO APROVEITAMENTO COMERCIAL DE AREIA RETIDA NO TRATAMENTO PRELIMINAR DA ETE ONÇA -MG
}

\section{ECONOMIC FEASIBILITY STUDY OF THE COMMERCIAL USE OF THE SAND RETIRED IN THE PRELIMINARY TREATMENT OF THE ETE ONÇA - MG}

\author{
W. R. SILVA ${ }^{1, *}$, K. I. H. M POAGUE ${ }^{1}$ and J. C. S NUNES ${ }^{1}$
}

${ }^{1}$ Federal University of Minas Gerais, Department of sanitary and environmental engineering, Belo Horizonte, Minas Gerais, Brazil

${ }^{*}$ Corresponding author. Federal University of Minas Gerais, Department of sanitary and environmental engineering, Belo Horizonte, Minas Gerais, Brazil, Phone: +55 31988416774

e-mail addressl:warley.ruas@gmail.com (W.R. SILVA).

\begin{tabular}{l} 
A R T I C L E I N F O \\
\hline Article history: \\
Received 2018-08-23 \\
Accepted 2018-10-01 \\
Available online 2018-10-31 \\
pa lav r a s-chave \\
Subprodutos \\
Reuso \\
Economia Circular \\
ke yw ords \\
By-productsnt \\
Reuse \\
Circular economy
\end{tabular}

A B S T R A C T
O reuso de subprodutos advindos do tratamento de esgotos sanitários é uma temática que vem
crescendo cada vez mais atualmente. Esse trabalho tem como objetivo realizar uma avaliação
econômica da reutilização da areia proveniente do tratamento preliminar da Estação de
Tratamento de Esgoto do Ribeirão do Onça (ETE Onça). Para isso foram avaliadas as etapas
necessárias para esse reuso que seriam: lavagem, secagem, controle de odor e proliferação
de vetores e higienização. Para a lavagem utilizou-se um lavador de areia. Na secagem optou-
se por utilizar pátios de secagem já construídos na ETE. Para o controle de odor, proliferação
de vetores e higienização foi calculada uma adição de cal. Entre os gastos e ganhos advindos
da venda da areia estimou-se que a partir do $20^{\circ}$ mês a ETE já haveria recuperados os gastos
iniciais e ao final de 2 anos conseguiria um lucro total de R $\$ 46.259,33$.
R E S U M O / R E S U M E N
The reuse of by-products from the treatment of sanitary sewage is a subject that is growing
more and more currently. This work aims to conduct an economic evaluation of the reuse of
the sand from the preliminary treatment of the Sewage Treatment Plant Ribeiração do Onça
(ETE Onça). For this, the steps necessary for this reuse were: washing, drying, odor control
and vector proliferation and hygiene. For washing was used a sand washer. In drying, it was
decided to use drying patios already built in the ETE. For the control of odor, vector
proliferation and hygienization an addition of lime was calculated. Among the expenses and
gains from the sale of sand, it was estimated that from the 20th month the ETE would have
recovered the initial expenses and at the end of 2 years it would obtain a total profit of R\$
$46.259,33$




\section{INTRODUCÃO}

$\mathrm{O}$ uso restaurativo de recursos e o aproveitamento comercial de subprodutos de Estações de Tratamento de Esgoto (ETEs) são temáticas que tem ganhado cada vez mais enfoque, especialmente na atual conjuntura de crise financeiro do país. O descarte de materiais retidos nas unidades de tratamento preliminar das ETEs em aterros sanitários, incluindo resíduos sólidos grosseiros e areia, é uma prática comum adotada no Brasil. Uma das alternativas para o reaproveitamento destes materiais é a utilização da areia removida nos desarenadores no setor de construção civil (BORGES et al, 2016). Ainda que esta prática seja incipiente, Borges (2014) e Gasparim (2013) propõe a readequação das ETEs Monjolinho (São Carlos) e ETE Barueri (Campinas) para a comercialização deste material. Ambos os autores realçam que além do benefício econômico, tal estratégia promove ganhos ambientais adicionais, uma vez que substituirá parcialmente a areia comercial advinda da atividade de extração de leitos e margens de rios, que causa intenso dano à qualidade das águas e formação de erosão.

$\mathrm{Na}$ maior ETE da América Latina com tecnologia de reatores anaeróbios de fluxo ascendente de manta de lodo (reatores UASB), ETE Onça, localizada em Belo Horizonte (Minas Gerais), são recolhidos e enviados para disposição em aterro sanitário, por mês, 101,45 toneladas de areia retida no desarenador da unidade de tratamento preliminar. Responsável por tratar os esgotos domésticos oriundos da Bacia do Ribeirão do Onça, contemplando os municípios de Contagem e Belo Horizonte, a estação possui capacidade máxima de operação de $2400 \mathrm{~L} / \mathrm{s}$, operando atualmente com vazão média de $1800 \mathrm{~L} / \mathrm{s}$, equivalente ao tratamento de esgoto doméstico de uma população de 800 mil habitantes.

Sob a perspectiva da econômica circular no âmbito do saneamento, o presente trabalho tem como objetivo principal estudar a viabilidade econômica de readequação da ETE Onça para aproveitamento comercial da areia proveniente do tratamento preliminar.

\section{METODOLOGIA}

A fim de tornar a areia retirada no tratamento de esgotos passível de aproveitamento comercial na indústria de construção civil, Borges (2014) estabelece um processo de quatro etapas após seu recolhimento:

1. Lavagem: possui o intuito de reduzir a matéria orgânica presente na areia. Os lavadores de areia são equipamentos que promovem a separação, lavagem, desaguamento e transporte da areia.

2. Secagem (desaguamento): objetiva reduzir a umidade e, consequentemente, o volume da areia após lavagem. Podem ser utilizadas estufas agrícolas como métodos de secagem natural, ou através de dispositivos mecânicos (geralmente incorporados ao sistema de lavagem) em estações maiores.

3. Controle de odor e proliferação de vetores: mesmo após a lavagem, uma pequena parcela de matéria orgânica permanece na areia, a qual pode sofrer processo de decomposição com liberação de odores (no caso de degradação anaeróbia) e atração de insetos. Para remediação, normalmente realiza-se a estabilização da biomassa com cal hidratada.

4. Higienização: apesar de não existir legislação brasileira referente à reutilização de areia proveniente de desarenadores de ETEs na construção civil, uma vez que o material pode ser utilizado como areia de contato primário (utilizadas em escolas e logradouros públicos como praias, parques, praças), a areia torna-se um potencial veículo de transmissão de microorganismos presentes no esgoto doméstico. Dentre as estratégias utilizadas para higienização da areia, Borges (2014) cita a insolação natural, cloração e calagem, sendo está última a mais eficiente em seus estudos. Gasparim (2013), ressalva, em concordância com Geyer (2001) e Lessa (2005), que a higienização por meio de tratamento químico é uma alternativa demasiadamente trabalhosa e onerosa. $\mathrm{O}$ autor ainda ressalta que em ETEs que adotam tecnologias de tratamento anaeróbio, o biogás gerado como subproduto do sistema, de alto potencial energético, pode ser utilizado como fonte de energia para o tratamento térmico da areia.

Para o presente trabalho, optou-se realizar a análise de viabilidade econômica de forma análoga a feita por Borges (2014) para a ETE Monjolinho. Levantou-se, portanto, os custos relativos a readequação de infraestrutura da ETE Onça, por meio da implantação de um sistema de aproveitamento de areia, composto pelas quatro etapas anteriormente descritas. Levou-se ainda em consideração o custo operacional composto de mão de obra, energia elétrica, água para lavagem e transporte da areia no interior da ETE e custos relativos à manutenção do equipamento de lavagem. Avaliou-se a disponibilidade de área física na ETE e ao seu redor para implantação das unidades propostas. Por fim, contrapôs-se o custo final de implantação, operação e manutenção com os ganhos financeiros advindos da comercialização da areia.

Foram considerados como premissas uma taxa de inflação anual de 5\%, taxa de reajuste de salário de 5\% ao ano e taxa de juros de $5 \%$.

\section{RESULTADOS E DISCUSSÃO}

\subsection{Lavagem}

A ETE Monjolinho remove em média 17,87 toneladas de resíduos sedimentáveis no desarenador, no entanto para estimativas de custo Borges (2014) adotou a remoção de 25 toneladas de areia por mês na estação. Como equipamento de lavagem, o autor adota um lavador mecânico modelo $H U B E R$ Coanda Sandwaschanlage RoSF4. De acordo com o site oficial da HUBER Tecnology - Waste Water Solutions (2017), este equipamento consegue reduzir o teor de matéria orgânica para menos de 3\%, além disso, proporciona simultaneamente a desidratação da areia atingindo um teor de sólidos secos de $90 \%$, além de operar com taxa de fluxo contínuo de até $3 \mathrm{~m}^{3}$ de sólidos por hora. 
Adotando como densidade de areia grossa seca o valor de 1,8 toneladas $/ \mathrm{m}^{3}$, um lavador do modelo HUBER Coanda Sandwaschanlage RoSF4, cujo preço em 2014 segundo Borges era cerca de $\mathrm{R} \$ 90.000,00$ atende-se à demanda de lavagem das 3,33 toneladas de areia removidos na ETE Onça por dia, operando aproximadamente 2 horas por dia. Corrigindo o preço do lavador de areia de 2014 adotando o Índice Nacional de Preços do Consumidor Amplo - IPCA (ADVNF BRASIL, 2017), estimasse que em 2017 o custo de aquisição do equipamento tenha aumentado para $\mathrm{R} \$ 108.207,77$ reais.

\subsection{Secagem}

Atualmente a estação conta com 4 leitos ( 20 x 10 metros) para secagem de escuma proveniente dos reatores UASB. Dos 24 reatores anaeróbios de fluxo ascendente de manta de lodo presentes na estação, um deste é reservado apenas para a recirculação e estabilização do lodo secundário dos decantadores. A fim de conciliar o aproveitamento da areia e a promoção da sustentabilidade da estação, optou-se por levantar um segundo cenário, no qual a escuma antes disposta nos leitos passará a ser co-digerida neste reator UASB juntamente com o lodo proveniente das unidades de decantação secundárias, permitindo que os leitos passem a ser utilizados para a secagem da areia. Induzindo, dessa forma, uma perspectiva de aumento da produção de biogás nos reatores e eliminando a necessidade da construção de novos pátios, reduzindo, portanto, o custo de implantação da infraestrutura para aproveitamento da areia

\subsection{Controle de odores, proliferação de vetores e higienização}

Para a etapa de higienização da areia, Borges (2014) concluiu que a calagem a partir da concentração de $10 \%$ de cal hidratada (em relação ao peso úmido da areia) foi suficiente para remoção eficiente de bactérias e ovos de helmintos, após uma semana de tratamento, tornando seguro o seu aproveitamento na indústria de construção civil. Portanto, para o montante de 101,4 toneladas de areia removida na ETE Onça por mês, serão necessários no mínimo 10,15 toneladas de cal hidratada. De acordo com o Sistema Nacional de Pesquisa de Custo e Índices da Construção Civil, o preço da cal hidratada CH-I para argamassas, em Minas Gerais, com referência ao ano de 2017 (CAIXA ECONÔMICA FEDERAL, 2017), corresponde a 59 centavos por kilograma. Portanto, para a higienização mensal da areia serão gastos aproximadamente $\mathrm{R} \$ 5.988,50$.

\subsection{Acessibilidade física das modificações propostas}

Quanto a disponibilidade de espaço físico implantação das unidades e readequações propostas, como pode ser visto pela Figura 1, existem duas áreas (marcadas como polígonos em amarelo na figura) disponíveis.

A primeira delas, representada pelo retângulo, corresponde a uma área de $18.139 \mathrm{~m}^{2}$ e já havia sido reservada no projeto de concepção da estação para a construção de novos reatores UASB com o intuito de ampliar a vazão atendida para $3600 \mathrm{~L} / \mathrm{s}$.

$\mathrm{O}$ segundo polígono, localizado à direita dos filtros biológicos percoladores e dos decantadores secundários, abrange uma área de $18.397 \mathrm{~m}^{2}$, local em que foram implantados os leitos de secagem para desidratação da escuma. Uma vez que os leitos de secagem ocupam uma pequena parcela dessa área $\left(800 \mathrm{~m}^{2}\right)$, consta-se que há espaço o suficiente para implantação das unidades e da infraestrutura proposta no presente projeto sem alterar a área prevista para expansão das unidades de tratamento secundário.

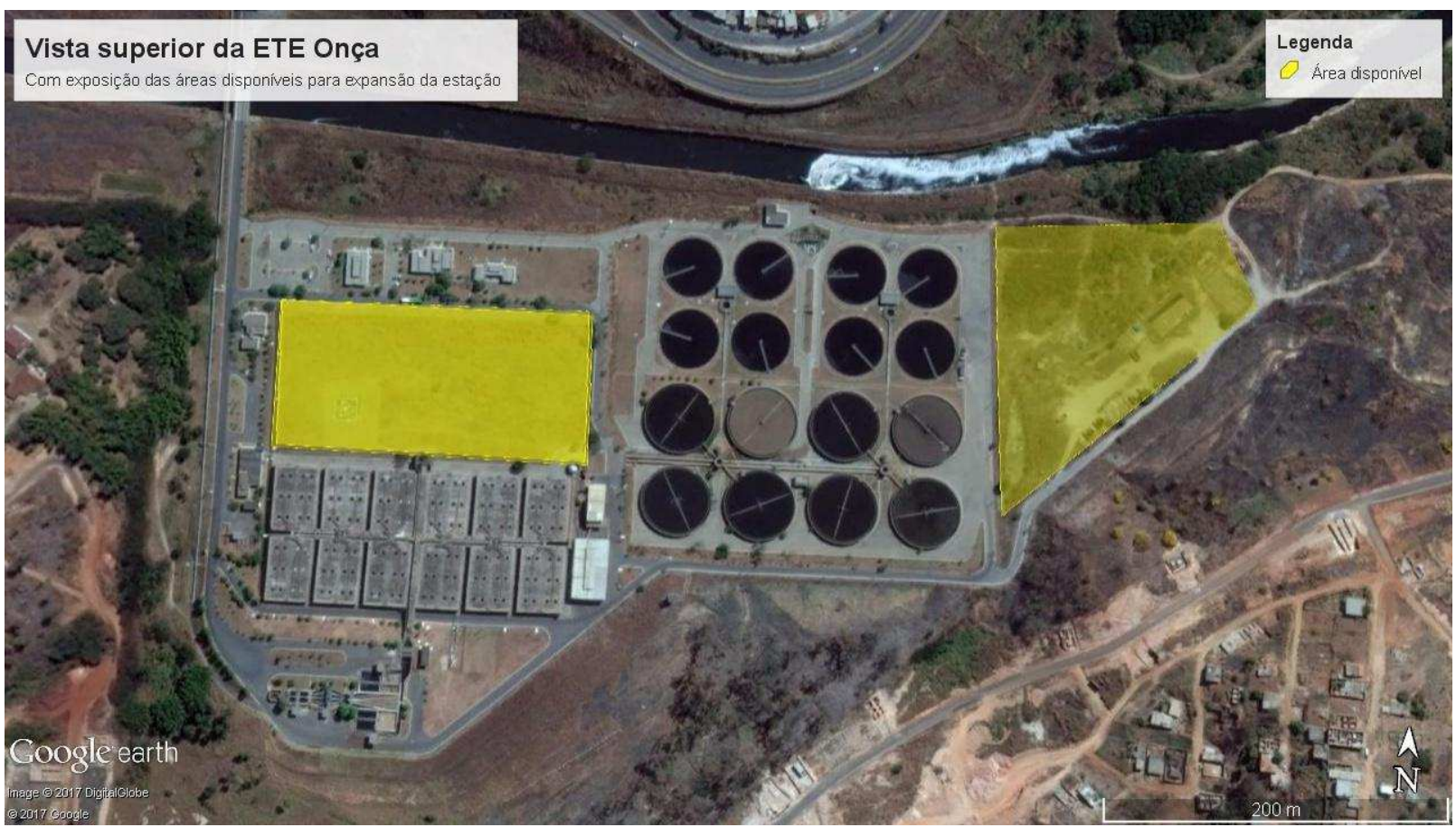

Figura 1 - Vista superior da ETE Onça com exposição das áreas disponíveis para expansão da estação. 


\subsection{Custo operacional e de manutenção.}

Com relação aos custos operacionais foram avaliados os gastos advindos da mão de obra necessária para operação do sistema, da energia elétrica gasta.

Segundo Borges (2014), a mão de obra necessária para todo o processo de lavagem, higienização e secagem da areia é de 4 horas de serviço para cada tonelada de areia produzida. Considerando o salário de um operador da COPASA com base no edital do último concurso público para preenchimento do quadro de servidores $(\mathrm{R} \$ 1689,06$ por 40 horas semanais ou $\mathrm{R} \$ 9,60 / \mathrm{h}$ ) (COPASA, 2018). Sendo assim, a partir da produção diária de areia na ETE Onça, tem-se que o gasto com mão de obra seria de $\mathrm{R} \$ 2.813,18$ por mês, considerando 22 dias úteis.

A energia consumida pelo lavador de areia utilizado segundo Borges (2014) é de 50,29 kWh por tonelada de areia. A energia cobrada pela CEMIG (2018) para rede de baixa tensão para demais classes é de $\mathrm{R} \$ 0,58684 / \mathrm{kWh}$. Tem-se então que o gasto com energia é de $\mathrm{R} \$ 2948,26$ por mês.

No que concerne ao gasto de água na etapa de lavagem, de acordo com informações fornecidas pelo corpo técnico da COPASA o volume de água computado na estação não é cobrado. Contudo, optou-se por incluir o custo de oportunidade da água utilizada na lavagem de deixou de ser comercializada pela COPASA (Custo de produção: $\mathrm{R} \$ 3,00 / \mathrm{m}^{3}$ ). Segundo Borges (2014) para lavagem de 1 tonelada de areia gasta-se $2,16 \mathrm{~m}^{3}$ de água. Para o presente contexto conclui-se que o processo de lavagem gastaria $219,13 \mathrm{~m}^{3}$ de água por mês, resultando em custo de oportunidade de R \$657,39/mês. Após a lavagem da areia este efluente seria reintroduzido na estação para posterior tratamento.

Recomenda-se, de forma análoga ao proposto por Gasparim (2014), análise de viabilidade da utilização do efluente clarificado como água para o lavador de areia, ao invés de seu total despejo no Ribeirão da Onça.

O custo de manutenção foi avaliado com base no valor do lavador de areia. Segundo Borges (2014) a vida útil deste tipo de equipamento é de aproximadamente 15 anos. Considerando um valor de manutenção de $10 \%$ do valor do equipamento temse que o gasto mensal com manutenção será em média de $\mathrm{R} \$ 60,12$ por mês (considerando o valor diluído em 15 anos).

Em virtude do porte da estação e do grande distanciamento entre as unidades torna-se necessário a aquisição de um caminhão para o transporte interno entre as unidades durante todo o processo de viabilização da areia. Para tanto considerou-se os custos relativos à aquisição de um caminhão basculante conforme Gasparim (2013), equivalente a $\mathrm{R} \$ 60.000,00$. Cabe ressaltar que no estudo de Gasparim realizado na ETE Barueri em São Paulo a produção de areia considerada foi de 50t/dia, cerca de 15 vezes superior à produção da estação do presente estudo. Como o Gasparim (2013) não específica as características do caminhão presume-se que este seja de grande porte. Para a ETE Onça a utilização deste caminhão apenas para transporte da areia, representaria uma grande capacidade ociosa, em vista da menor produção de areia. Contudo, pondera-se que o caminhão basculante poderá ser utilizado para carregamento de outros materiais como, por exemplo, o lodo da estação, e resíduos sólidos provenientes da etapa preliminar.

A aquisição do sistema de lavagem assim como do caminhão basculante será parcelado em 10 vezes considerando a taxa de juros de 5\%. A taxa de inflação foi aplicada sobre os custos operacionais referentes a água e energia elétrica, sobre o valor de venda da areia e nos custos referentes aos materiais para higienização.

\subsection{Custos x Ganhos financeiros}

Em relação aos ganhos financeiros com o reaproveitamento da areia, de acordo com dados do Sistema Nacional de Pesquisa de Custos e Índices da Construção Civil, o preço da areia por $\mathrm{m}^{3}$, em Minas Gerais com referência ao ano de 2017 (CAIXA ECONÔMICA FEDERAL, 2017), varia de $\mathrm{R} \$ 58,33$ a $\mathrm{R} \$ 67,00$ de acordo com granulometria (areia grossa, média e fina). Considerando a densidade de $1800 \mathrm{~kg} / \mathrm{m}^{3}$, e o preço médio de $\mathrm{R} \$ 63,00 / \mathrm{m}^{3}$, o preço final de venda da areia da ETE Onça é estimado inicialmente em R $\$ 35,00 /$ tonelada. Adiciona-se a esse valor, o custo de disposição final da areia em aterro sanitário que não mais será necessário, de $\mathrm{R} \$ 160,00 /$ tonelada de acordo com Borges (2014) com referência de 2014, com reajuste segundo o IPCA (ADVNF BRASIL, 2017) em R $\$ 192,36 /$ tonelada. Portanto, cada tonelada de areia aproveitada na estação, gerará inicialmente um ganho financeiro de $\mathrm{R} \$ 227,36$.

A aquisição do sistema de lavagem assim como do caminhão basculante será parcelado em 10 vezes considerando a taxa de juros de 5\%. A taxa de inflação foi aplicada sobre os custos operacionais referentes a água e energia elétrica, sobre o valor de venda da areia e nos custos referentes aos materiais para higienização.

Realizando uma projeção financeira em um intervalo de 24 meses após a instalação da infraestrutura necessária para o aproveitamento da areia e a sua venda para o setor de construção civil, constata-se que a partir do vigésimo mês o investimento inicial é totalmente pago e os ganhos são superiores aos gastos (saldo positivo). Ao final do vigésimo quarto mês, a unidade de aproveitamento de areia removida do desarenador proporcionará um ganho de $\mathrm{R} \$ 46.259,33$ (Tabela 1).

\section{CONCLUSÃO}

A partir dos resultados encontrados, constata-se que o aproveitamento da areia proveniente dos desarenadores como material para a indústria de construção civil é economicamente viável, conseguindo pagar todo o investimento feito e obter lucro a partir do vigésimo mês. Cabe ressaltar que trata-se apenas de uma estimativa de custo preliminar e que depende do porte da ETE e das condições locais, sendo este estudo um caso específico do contexto da ETE Onça. 
Tabela 1 - Projeção financeira gastos/ganhos com a implantação da unidade de reaproveitamento de areia

\begin{tabular}{|c|c|c|c|c|c|c|c|}
\hline Mês & $\begin{array}{l}\text { Implantação } \\
\text { lavador de } \\
\text { areia }\end{array}$ & $\begin{array}{l}\text { Higienização } \\
\text { da areia }\end{array}$ & $\begin{array}{c}\text { Custos } \\
\text { Operacionais }\end{array}$ & Manutenção & $\begin{array}{l}\text { Aquisição de } \\
\text { caminhão }\end{array}$ & $\begin{array}{c}\text { Areia } \\
\text { vendida }\end{array}$ & Total \\
\hline 1 & $-16.231,17$ & $-5.988,50$ & $-6.418,83$ & $-60,12$ & $-9.000,00$ & $23.064,53$ & $-14.634,09$ \\
\hline 2 & $-15.690,13$ & $-5.988,50$ & $-6.418,83$ & $-60,12$ & $-8.700,00$ & $23.064,53$ & $-28.427,13$ \\
\hline 3 & $-15.149,09$ & $-5.988,50$ & $-6.418,83$ & $-60,12$ & $-8.400,00$ & $23.064,53$ & $-41.379,14$ \\
\hline 4 & $-14.608,05$ & $-5.988,50$ & $-6.418,83$ & $-60,12$ & $-8.100,00$ & $23.064,53$ & $-53.490,11$ \\
\hline 5 & $-14.067,01$ & $-5.988,50$ & $-6.418,83$ & $-60,12$ & $-7.800,00$ & $23.064,53$ & $-64.760,04$ \\
\hline 6 & $-13.525,97$ & $-5.988,50$ & $-6.418,83$ & $-60,12$ & $-7.500,00$ & $23.064,53$ & $-75.188,93$ \\
\hline 7 & $-12.984,93$ & $-5.988,50$ & $-6.418,83$ & $-60,12$ & $-7.200,00$ & $23.064,53$ & $-84.776,78$ \\
\hline 8 & $-12.443,89$ & $-5.988,50$ & $-6.418,83$ & $-60,12$ & $-6.900,00$ & $23.064,53$ & $-93.523,60$ \\
\hline 9 & $-11.902,85$ & $-5.988,50$ & $-6.418,83$ & $-60,12$ & $-6.600,00$ & $23.064,53$ & $-101.429,37$ \\
\hline 10 & $-11.361,82$ & $-5.988,50$ & $-6.418,83$ & $-60,12$ & $-6.300,00$ & $23.064,53$ & $-108.494,11$ \\
\hline 11 & - & $-5.988,50$ & $-6.418,83$ & $-60,12$ & & $23.064,53$ & $-97.897,03$ \\
\hline 12 & - & $-5.988,50$ & $-6.418,83$ & $-60,12$ & & $23.064,53$ & $-87.299,95$ \\
\hline 13 & - & $-6.287,93$ & $-6.739,77$ & $-60,12$ & & $24.217,76$ & $-76.170,01$ \\
\hline 14 & - & $-6.287,93$ & $-6.739,77$ & $-60,12$ & & $24.217,76$ & $-65.040,07$ \\
\hline 15 & - & $-6.287,93$ & $-6.739,77$ & $-60,12$ & & $24.217,76$ & $-53.910,13$ \\
\hline 16 & - & $-6.287,93$ & $-6.739,77$ & $-60,12$ & & $24.217,76$ & $-42.780,19$ \\
\hline 17 & - & $-6.287,93$ & $-6.739,77$ & $-60,12$ & & $24.217,76$ & $-31.650,25$ \\
\hline 18 & - & $-6.287,93$ & $-6.739,77$ & $-60,12$ & & $24.217,76$ & $-20.520,31$ \\
\hline 19 & - & $-6.287,93$ & $-6.739,77$ & $-60,12$ & & $24.217,76$ & $-9.390,37$ \\
\hline 20 & - & $-6.287,93$ & $-6.739,77$ & $-60,12$ & & $24.217,76$ & $1.739,57$ \\
\hline 21 & - & $-6.287,93$ & $-6.739,77$ & $-60,12$ & & $24.217,76$ & $12.869,51$ \\
\hline 22 & - & $-6.287,93$ & $-6.739,77$ & $-60,12$ & & $24.217,76$ & $23.999,45$ \\
\hline 23 & - & $-6.287,93$ & $-6.739,77$ & $-60,12$ & & $24.217,76$ & $35.129,39$ \\
\hline 24 & - & $-6.287,93$ & $-6.739,77$ & $-60,12$ & & $24.217,76$ & $46.259,33$ \\
\hline
\end{tabular}

\section{R E F E R E N C I A S}

ADVFN Brasil. Indicadores Econômicos - IPCA. 2017. Disponível em: $<$ https://br.advfn.com/indicadores/ipca $>$. Acesso em: 17 de novembro de 2017.

BORGES, N. B. Aproveitamento dos resíduos gerados no tratamento preliminar de estações de tratamento de esgoto. 2014. 238 f. Tese (Doutorado) - Programa de Pós-Graduação e Área de concentração em Hidráulica e Saneamento - Escola de Engenharia de São Carlos, Universidade de São Paulo, São Carlos, 2014.

BORGER, N. B; CAMPOS, J. R; PABLOS, J. M; FERREIRA, G. T. Potencialidade da utilização da areia removida em desarenadores de estação de tratamento de esgoto na construção civil, como material alternativo à areia comercial comum. Revista DAE, v. 64, n. 203, p. 64-79, 2016.

CAIXA ECONÔMICA FEDERAL. Downloads. SINAPI - a partir de Jul/2009 - MG. 2017. Disponível em: <http://www.caixa.gov.br/site/Paginas/downloads.aspx\# categoria_648>. Acesso em: 17 de novembro de 2017.

CEMIG - Companhia Energética de Minas Gerais. Valores de Tarifa e Serviços. 2018. Disponível em: $<$ https://www.cemig.com.br/pt-

br/atendimento/Paginas/valores_de_tarifa_e_servicos.as px>. Acesso em: 18 de out. 2018.
COPASA - Companhia de Saneamento de Minas Gerais. Concursos. 2018. Disponível em: http://www.copasa.com.br/wps/portal/internet/acopasa/concurso-publico. Acesso em: 18 de out. 2018.

GEYER, A. L. B. Contribuição ao estudo da disposição final e aproveitamento da cinza de lodo de estações de tratamento de esgotos sanitários como adição ao concreto. 2001. 238 f. Tese (Doutorado) - Programa de Pós-Graduação em Engenharia Civil - Universidade Federal do Rio Grande do Sul, Porto Alegre, 2001.

GASPARIM, J. C. Viabilidade de aproveitamento de resíduos de tratamento de esgotos na construção civil. 2013. 227 f. Tese (Doutorado) - Programa de PósGraduação em Engenharia Civil, na área de concentração de Recursos Hídricos, Energéticos e Ambientais Universidade Estadual de Campinas, Campinas, 2013.

LESSA, G. T. Contribuição ao estudo da viabilidade da utilização do lodo de estação de tratamento biológico de esgoto misto na construção civil. 2005. $135 \mathrm{f}$. Dissertação (Mestrado Profissional) - Modalidade Profissionalizante Ênfase em Engenharia Ambiental e Tecnologias Limpas - Universidade Federal do Rio Grande do Sul, Porto Alegre, 2005. 